\title{
ERRATUM
}

\section{Accuracy of oncologist assessments of psychiatric problems in cancer inpatients-ERRATUM}

\section{DAISUKE YASUGI, HIDETAKA TAMUNE, JITSUKI SAWAMURA AND KATSUJI NISHIMURA}

doi: https://doi.org/10.1017/S147895151700027X, Published by Cambridge University Press, 03 May 2017.

The academic degrees for authors Yasugi and Sawamura are incorrect in the published article. The proper byline should read as follows:

DAISUKE YASUGI, M.D., HIDETAKA TAMUNE, M.D., JITSUKI SAWAMURA, M.D., PH.D, AND KATSUJI NISHIMURA, M.D., PH.D.

In addition, the following correction should also be noted:

In Figure 1, the word "Psychiatrists" is missing in the Y axis label and categories are missing from the $\mathrm{X}$ axis. An updated Figure 1 file is included below:

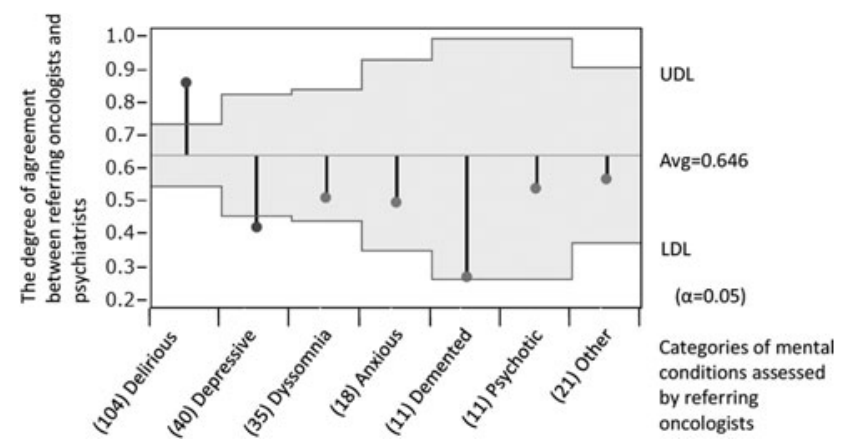

The author and publisher regret these errors.

\section{REFERENCE}

Yasugi, D., Tamune, H., Sawamura, J., Nishimura, K. (2017). Accuracy of oncologist assessments of psychiatric problems in cancer inpatients. Palliative and Supportive Care. doi: 10.1017/S147895151700027X 